\title{
Scar tissue orientation in unsutured and sutured corneal wound healing
}

Gerrit R J Melles, Perry S Binder, W Houdijn Beekhuis, Robert H J Wijdh, Max N Moore, Janet A Anderson, Nirmala SundarRaj

\begin{abstract}
Aims-This study aimed to evaluate stromal wound healing morphology in short term unsutured compared with sutured corneal wounds, to define regional variation in healing within radial keratotomy wounds.

Methods-Stromal scar tissue orientation (fibroblast and collagen fibre orientation) was analysed in unsutured and adjacent sutured keratotomy wounds in monkeys, 2 to 9 weeks after surgery, using light and transmission electron microscopy.

Results-At 2 to 4 weeks, scar tissue orientation was transverse to the wound edge in unsutured wounds, but sagittal in sutured wounds. At 5 to 9 weeks, a reorientation of scar tissue sagittal to the wound was seen in the unsutured wounds, proceeding from the posterior to anterior wound regions. In sutured wounds, a scar tissue reorientation transverse to the wound was seen, proceeding from the anterior wound region in a posterior direction.

Conclusions-Within the same cornea, sutured and unsutured wounds showed opposite patterns of healing. Sutured wounds initially healed more slowly, but obtained pseudolamellar continuity over time. In contrast, healing of unsutured wounds was characterised by an early approximation towards lamellar repair that was followed by an ineffective reorganisation of the scar. This latter pattern of healing, that may be associated with a variable weakening of the wound, may relate to the clinical findings of unpredictability and/or progression of refractive effect following radial keratotomy.

(Br f Ophthalmol 1995; 79: 760-765)
\end{abstract}

Healing of unsutured corneal wounds has been described to be delayed and abnormal, compared with a progression towards normal stromal anatomy in sutured wounds. ${ }^{1-3}$ This difference may result from a lower inflammatory response in the absence of sutures, ${ }^{2}$ and/or from wound gaping with epithelial plug development in early unsutured wounds. ${ }^{14}$ Since recent studies suggested that the morphology of unsutured wounds is not significantly altered by the presence of adjacent sutured wounds within the same monkey cornea, ${ }^{3}$ a lower inflammatory response may not solely explain abnormal healing of unsutured wounds. Unstable opposition of the wound edges may interfere with healing owing to eyelid movement and diurnal intraocular pressure variation. The presence of ectopic epithelium within unsutured wounds may also affect the organisation of the stromal scar. ${ }^{5-11}$

In a recent study, ${ }^{12}$ the scar tissue morphology of unsutured wounds in humans and monkeys was found to vary over the depth of the wound. Anterior regions showed near anatomical, pseudolamellar restoration whereas the midposterior regions were found to be disorganised. It was hypothesised that regional variation in healing may result from differences in healing rates within the wound, from mechanical factors associated with epithelial plug elimination, or from different intrinsic healing properties among stromal layers. To determine further how asymmetrical repair of an individual unsutured wound is established, early wound healing phases may be analysed in an animal model representative for healing in humans.

To evaluate the chronological phases in early wound healing, and to determine factor(s) contributing to regional variation in healing, we studied light and transmission electron microscopic features of scar tissue in unsutured compared with sutured wounds within the same monkey eye.

\section{Materials and methods}

Radial keratotomy (RK) procedures were performed by one of us (GM), in seven male monkeys (Macaca mulatta), 5-7 kg in weight, aged 7-8 years. All animals were housed and treated according to the Association for Research in Vision and Ophthalmology resolution for animal care.

Each monkey was anaesthetised with ketamine (ketamine $100 \mathrm{mg} / \mathrm{ml}$, Tesink Veterinary Products, Oudewater, Netherlands) and acepromazine (Vetaranquil 10 $\mathrm{mg} / \mathrm{ml}$, Sanory, Maassluis, Netherlands). Eyelids were swabbed with $10 \%$ iodine (Betadine, Dagra, Diemen, Netherlands), and covered with a sterile plastic drape 

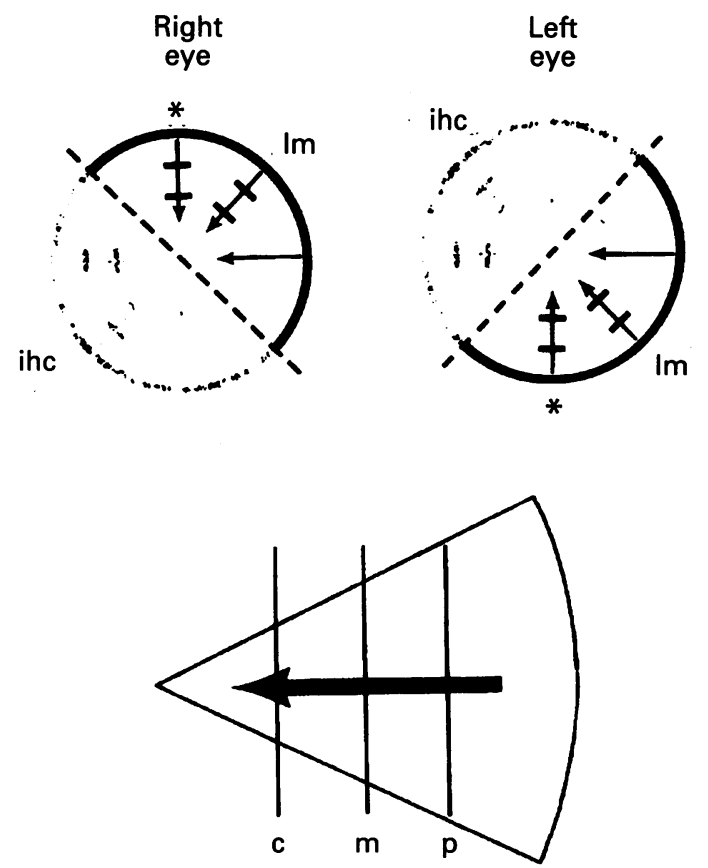

Figure 1 Keratotomy and suture patterns performed in 14 monkey corneas. Incisions in corneal halves designated for light microscopy (Im, non-shaded halves) were sectioned in the central $(c)$, mid $(m)$, and peripheral $(p)$ portions. Reopened and sutured wounds (asterisks) were not analysed in the present study. The shaded corneal halves have been used for immunohistochemical (ihc) analysis.

(Inzisionsfolie $15 \times 26 \mathrm{~cm}$, Johnson and Johnson, Amersfoort, Netherlands). A double edged diamond blade (Drukker International, Amsterdam, Netherlands) was set to achieve $90 \%$ of the thinnest ultrasonic central corneal reading, to avoid corneal perforation (Humphrey ultrasonic pachometer, model 850, Humphrey, San Leandro, CA, USA). Blade extension was measured monocularly under the operating microscope (Zeiss, Weesp, Netherlands) at maximum magnification using a coin gauge. After marking a $3.0 \mathrm{~mm}$ optical clear zone (OCZ) centred on the pupil (Moria Instruments, Paris, France), centripetal (limbus to OCZ) incisions were made using the perpendicular cutting edge, with the eye stabilised with a toothed forceps at the opposite limbus $180^{\circ}$ away.

All monkeys underwent a bilateral, six incision RK procedure; three semiradial incisions were placed in each half of the cornea. Incisions at 1.30, and 7.30 o'clock in the right eye, at 4.30, and 10.30 o'clock in the left eye were closed with two interrupted 10/0 nylon sutures on a four wire needle (Fig 1) (Alcon monofilament Nylon, Gorinchem, Netherlands). The knots were buried. At various postoperative time intervals, incisions at 12.00 , and 9.00 o'clock in the right eye, at 6.00 and 9.00 o'clock in the left eye were reopened and closed with two interrupted sutures (Fig 1). At the end of each operation, $0.5 \mathrm{ml}$ gentamicin sulphate (Garamycin $40 \mathrm{mg} / \mathrm{ml}$, Schering-Plough, Weesp, Netherlands) was injected subconjunctivally.

Monkeys were killed using an overdose of intravenous sodium pentobarbitone (Euthesate $200 \mathrm{mg} / \mathrm{ml}$, Apharma, Arnhem, Netherlands). Eyes were enucleated and corneoscleral rims with a suture identifying the
12 o'clock meridian of the scleral flap, were obtained by incising the sclera for $360^{\circ}$ anterior to the equator leaving a $3 \mathrm{~mm}$ scleral rim, gently removing the anterior uveal tissue. With a razor blade knife, corneas were cut in half (endothelial side to epithelial side) perpendicularly to the incisions at 1.30 , and 7.30 o'clock in the right eye, to those at 4.30 , and 10.30 o'clock in the left eye (Fig 1).

Superior-nasal corneal halves of the right eye, and inferior-temporal halves of the left eye, intended for light microscopy (LM) and transmission electron microscopy (TEM) (Fig 1), were fixed in $2.5 \%$ glutaraldehyde $/ 2 \%$ paraformaldehyde in $0.1 \mathrm{M}$ cacodylate buffer (pH 7.3, $340 \mathrm{mOsm}$ ), and post-fixed in $2 \%$ osmium tetroxide in $0.1 \mathrm{M}$ cacodylate buffer for 1 hour. Specimens were then dehydrated in a graded series of ethanol followed by intermediate changes of propylene oxide and embedded in epoxy resin (Poly bed Epon 812, Polysciences, Warmington, PA, USA). Ultrathin sections of one unsutured and one sutured wound of each monkey were placed on slot grids, that were coated with a Formvar film ( $1 \%$ Formvar ethylene dichloride, Balzers Union Aktien Gesellschaft, Balzers, Lichtenstein) to allow evaluation of the whole wound in the same section, using a transmission electron microscope at $60 \mathrm{kV}$ (JEM-1200 EX electron microscope, Jeol Ltd, Tokyo, Japan). Inferior-temporal corneal halves from the right eye, and superior-nasal halves from the left eye were frozen for immunohistochemical analysis (Fig 1).

One animal was killed at $2,3,4,5,6,7$, and 9 weeks after the primary surgery, and two unsutured and two sutured wounds from both eyes of the same animal (Fig 1) were evaluated for each postoperative time interval. Each incision was divided into a central, mid and peripheral portion* (Fig 1), and $1 \mu \mathrm{m}$ sections were cut perpendicularly to each incision portion. Sections were stained with Mallory's azure II-methylene blue, counterstained with basic fuchsin, ${ }^{13}$ and photographed at $150 \times$ magnification (Olympus Vanox light microscope, Olympus Optical Co Ltd, Tokyo, Japan). In photomicrographs printed at $250 \times$, the wound area was divided into six equal stromal regions: anterior regions I and II, mid regions III and IV, and posterior regions $V$ and VI (Fig 2). Using an arbitrary numerical scoring model previously described,12 14 fibroblast orientation within each region was scored from 3 to 0 ( 3 =transverse - that is, perpendicular to the wound; $0=$ sagittal - that is, parallel to the wound).

Apparent lamellar continuity across the wound at an ultrastructural level was generally reflected by fibroblast orientation at a light microscopic level, 381214 and was not scored separately. Fibroblasts in each wound were evaluated for the presence of myofibroblastic characteristics (bundles of microfilaments, a cortical microfilament network, filaments

*For clarity of nomenclature throughout the text, incision depth was subdivided into anterior, mid and posterior 'regions', and incision length into central, mid, and peripheral 'portions' 

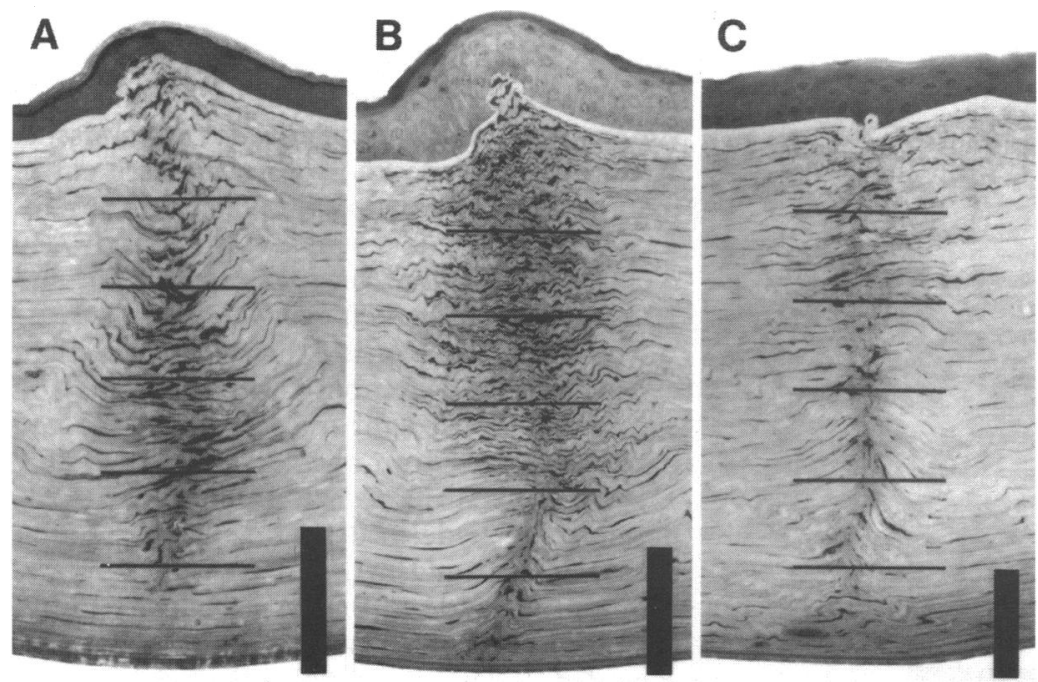

3

6
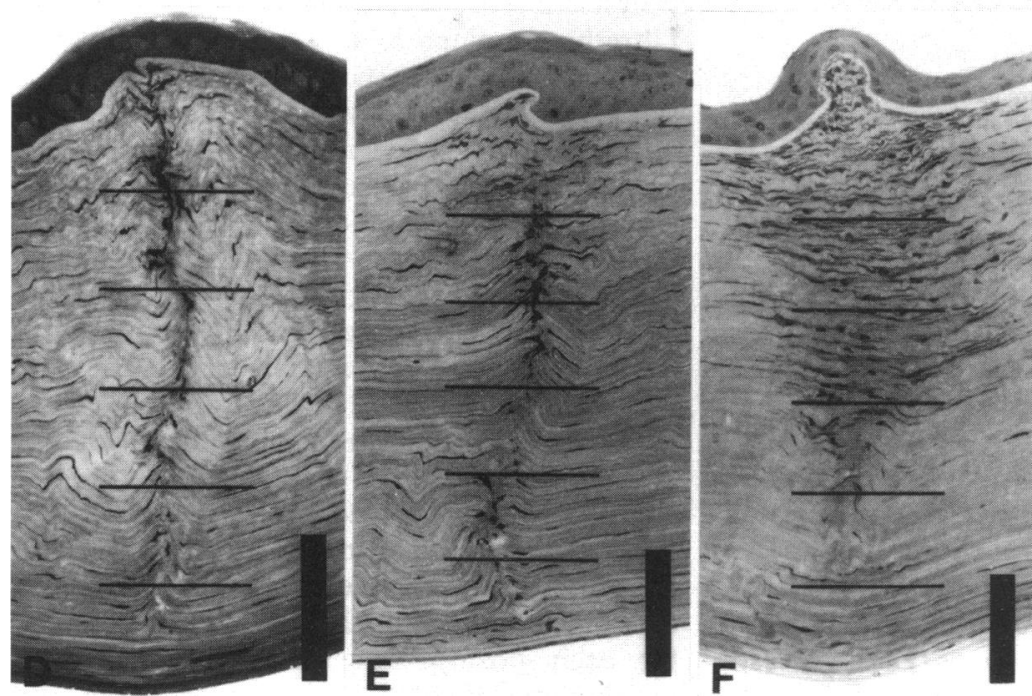

Figure 2 Unsutured $(A-C)$ and sutured $(D-F)$ wounds within the same monkey corneas, 3 weeks ( $A$ and $D$ ), 6 weeks ( $B$ and $E$ ), and 9 weeks ( $C$ and $F$ ) after surgery. Wound healing morphology was evaluated in six equal stromal regions (I to VI, as indicated by the horizontal bars in each photograph). At 3 weeks, the unsutured wound shows transverse fibroblast orientation in all regions $(A)$, at 6 weeks in regions I to IV $(B)$, and at 9 weeks in regions $I$ and $I I(C)$. Reorientation of posterior fibroblast sagittal to the wound appears to progress from posterior to anterior over time. The sutured wounds show transverse

fibroblast orientation in none of the regions at 3 weeks (D), at 6 weeks in region $I(E)$, and at 9 weeks in regions I to III (F). Establishment of transverse fibroblast orientation appears to progress from anterior to posterior over time. (Mallory's azure II-methylene blue/basic fuchsin, vertical bar $=100 \mu \mathrm{m}$ ).

radiating from the cell membrane, and the presence of extensive rough endoplasmatic reticulum, microtubules, and Golgi apparatus). ${ }^{416}$ Data of similar types of wounds in both

Table 1 Scoring fibroblast orientation in unsutured wounds

\begin{tabular}{|c|c|c|c|c|c|c|c|c|c|}
\hline \multirow{2}{*}{$\begin{array}{l}\text { Wound } \\
\text { region }\end{array}$} & \multicolumn{7}{|c|}{ Weeks postoperative } & \multirow[b]{2}{*}{ Slope } & \multirow{2}{*}{$\stackrel{p}{\text { Value }}$} \\
\hline & 2 & 3 & 4 & 5 & 6 & 7 & 9 & & \\
\hline I & $2 \cdot 5$ & $3 \cdot 0$ & $3 \cdot 0$ & $3 \cdot 0$ & $3 \cdot 0$ & $2 \cdot 5$ & $2 \cdot 0$ & -0.09 & $0 \cdot 19$ \\
\hline II & $1 \cdot 5$ & $3 \cdot 0$ & $2 \cdot 5$ & $2 \cdot 5$ & $3 \cdot 0$ & $2 \cdot 5$ & 2.5 & +0.07 & 0.45 \\
\hline III & $1 \cdot 5$ & $2 \cdot 0$ & $2 \cdot 5$ & $1 \cdot 0$ & $2 \cdot 0$ & $1 \cdot 0$ & 0.5 & $-0 \cdot 18$ & 0.13 \\
\hline IV & $1 \cdot 5$ & $2 \cdot 0$ & $2 \cdot 5$ & 0.5 & 0.5 & 0.0 & 0.5 & -0.27 & 0.07 \\
\hline V & $1 \cdot 0$ & $1 \cdot 0$ & 1.5 & 0.0 & 0.0 & 0.0 & 0.0 & -0.20 & 0.05 \\
\hline & ndf & $(0.0)$ & $(1 \cdot 0)$ & $(0 \cdot 0)$ & nd & $(0 \cdot 0)$ & nd & - & - \\
\hline Average & $1 \cdot 6$ & $2 \cdot 2$ & $2 \cdot 4$ & $1 \cdot 4$ & $1 \cdot 7$ & $1 \cdot 2$ & $1 \cdot 1$ & & \\
\hline $\operatorname{SD}(n-1)$ & 0.5 & 0.8 & 0.5 & $1 \cdot 3$ & $1 \cdot 4$ & $1 \cdot 3$ & $1 \cdot 1$ & & \\
\hline
\end{tabular}

Scoring fibroblast orientation from 3 (=transverse - that is, perpendicular to the wound) to 0 (=sagittal - that is, parallel to the wound).

*The wound area was divided in six stromal regions: anterior regions I and II, mid regions III and IV, and posterior regions V and VI. + Regression analysis per wound region; testing slope $=0$. $\ddagger$ nd $=$ no data. $₫$ Average of regions $I$ to $V$. corneas of each animal were averaged (Tables 1 and 2). The analysis of reopened and sutured wounds (Fig 1) was not included in this report (unpublished data).

Statistical analysis was performed using NCSS regression analysis (Number Cruncher Statistical Systems, Dr J L Hintze, Kaysville, UT, USA).

\section{Results}

We evaluated 14 unsutured and 14 adjacent sutured wounds, 2-9 weeks after surgery, in a monkey model. At all postoperative time intervals, unsutured wounds showed complete stromal wound closure except for one superior wound in the right cornea of monkey 7 , which contained a superficial epithelial plug 9 weeks after surgery. Wound healing morphology in unsutured and sutured wounds appeared to be comparable between mate eyes; wound morphology did not differ among wounds in superior-nasal corneal halves of the right eye, and inferior-temporal halves of the left eye (Fig 1).

Two to 4 weeks after surgery, unsutured wounds showed an overall transverse fibroblast orientation over the entire wound depth (Fig 2A; Table 1). Elongated cells with multiple cell-cell interactions were seen across the wound. Sutured wounds had an overall sagittal fibroblast orientation; clusters of fibroblasts were often seen in the anterior and mid stromal regions (Fig 2D; Table 2). Ultrastructurally, both types of wounds showed an amorphous extracellular matrix with a sparse distribution of collagen fibres along the fibroblasts.

At 5 and 6 weeks, unsutured wounds showed fibroblasts with a transverse orientation in the anterior and mid regions, but a sagittal orientation in the posterior regions (Fig 2B; Table 1). In sutured wounds, fibroblast orientation was transverse in the anterior wound regions, but sagittal in the midposterior regions (Fig 2E; Table 2). In both types of wounds, transverse fibroblast orientation was associated with bundles of collagen fibres across the wound. These bundles were continuous with isodirected fibres of one or more lamellae at both of the wound edges; pseudolamellae were present in the anterior and mid regions of unsutured wounds (Fig 3) and in the anterior regions of sutured wounds.

At 7 and 9 weeks, unsutured wounds displayed a transverse fibroblast orientation in the anterior regions only, whereas the mid and posterior regions had a sagittal cell orientation (Fig 2C; Table 1). Transverse fibroblast orientation in sutured wounds was present in the anterior and mid regions (Fig 2F; Table 2), although the degree of transverse cell orientation varied over the length of the incisions. Again, collagen fibre continuity across the wound was associated with transverse fibroblast orientation - that is, pseudolamellae were seen in the anterior regions of unsutured wounds, and in the anterior and mid regions of sutured wounds. 
Table 2 Scoring fibroblast orientation in sutured wounds

\begin{tabular}{|c|c|c|c|c|c|c|c|c|c|}
\hline \multirow{2}{*}{$\begin{array}{l}\text { Wound } \\
\text { region } \star\end{array}$} & \multicolumn{7}{|c|}{ Weeks postoperative } & \multirow[b]{2}{*}{ Slope } & \multirow{2}{*}{$\stackrel{p}{\text { Value }}$} \\
\hline & 2 & 3 & 4 & 5 & 6 & 7 & 9 & & \\
\hline I & 1.5 & $2 \cdot 0$ & 1.5 & $2 \cdot 0$ & $2 \cdot 5$ & $2 \cdot 5$ & 2.5 & $+0 \cdot 16$ & 0.02 \\
\hline II & 0.5 & 0.0 & 1.5 & $1 \cdot 0$ & $2 \cdot 0$ & 3.0 & $2 \cdot 0$ & +0.33 & 0.04 \\
\hline III & 0.0 & 0.0 & 0.5 & 0.5 & 0.5 & 2.5 & 1.5 & +0.29 & 0.04 \\
\hline IV & 0.0 & 0.0 & $0 \cdot 0$ & 0.0 & 0.0 & 1.5 & $1 \cdot 0$ & +0.19 & 0.06 \\
\hline V & 0.0 & 0.0 & $0 \cdot 0$ & 0.0 & 0.0 & 0.5 & 0.0 & +0.03 & 0.45 \\
\hline & $(0.0)$ & $(0 \cdot 0)$ & $(0 \cdot 0)$ & $(0 \cdot 0)$ & ndł & $(0 \cdot 0)$ & $(0 \cdot 0)$ & - & - \\
\hline Average $\$$ & 0.4 & $0 \cdot 4$ & 0.7 & 0.7 & $1 \cdot 0$ & $2 \cdot 0$ & $1 \cdot 4$ & & \\
\hline$S D(n-1)$ & 0.7 & 0.9 & $0 \cdot 8$ & $0 \cdot 8$ & $1 \cdot 2$ & $1 \cdot 0$ & 1.0 & & \\
\hline
\end{tabular}

Scoring fibroblast orientation from 3 (=transverse - that is, perpendicular to the wound) to 0 (=sagittal - that is, parallel to the wound).

*The wound area was divided in six stromal regions: anterior regions I and II, mid regions III and IV, and posterior regions $\mathrm{V}$ and VI. $\nmid$ Regression analysis per wound region; testing slope $=0$. $\ddagger$ nd $=$ no data. \$Average of regions $I$ to $V$.

In contrast with earlier time intervals, the scar tissue in the mid and posterior regions of unsutured wounds was disorganised, with an absence of collagen fibre continuity across the wound (Fig 3). Myofibroblastic cell characteristics were not observed in sutured or unsutured wounds at any postoperative time interval.

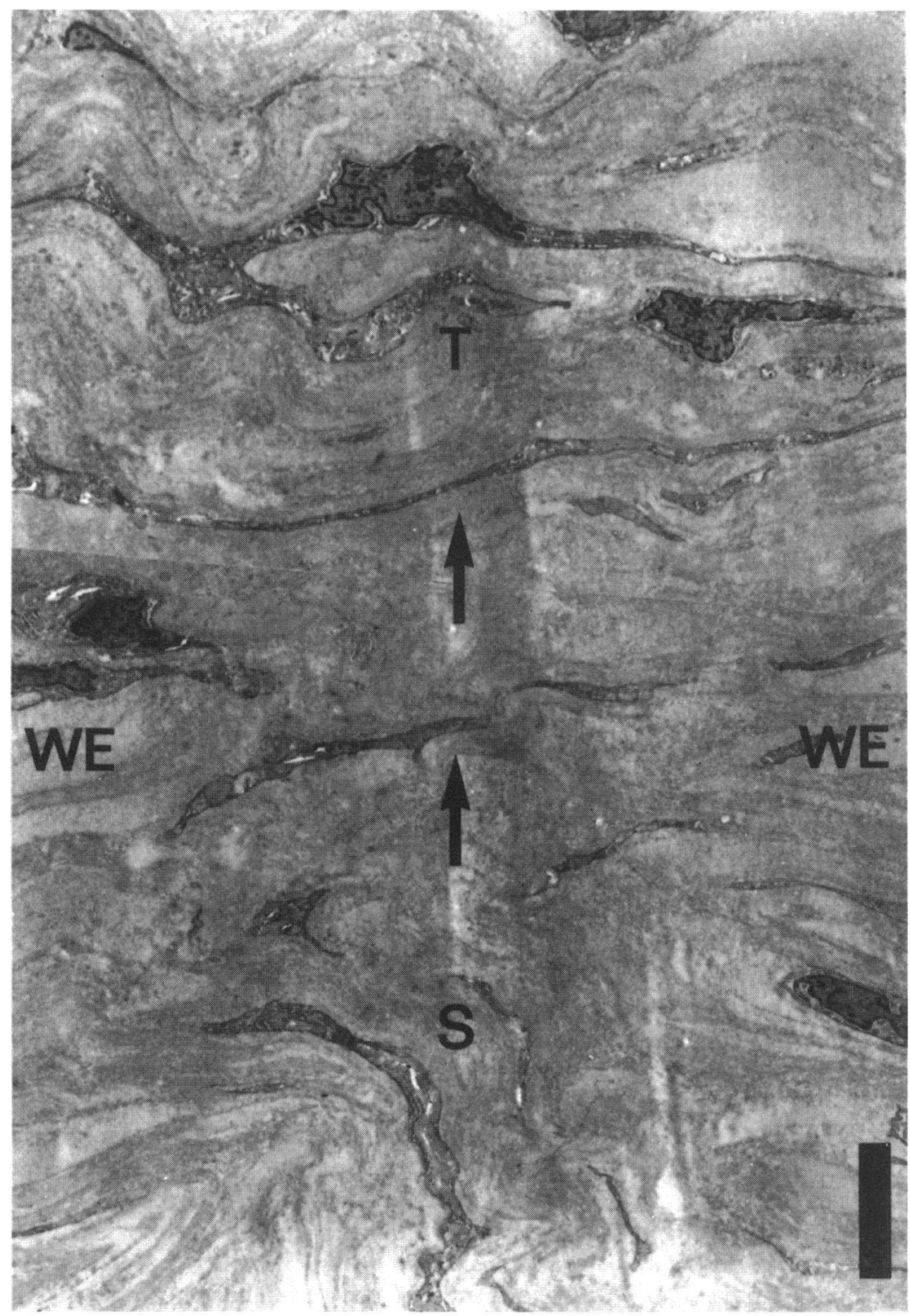

Figure 3 In the mid portion of an unsutured wound 6 weeks after surgery, a transition zone is visible between transversely $(T)$ and sagittally $(S)$ oriented scar tissue. Transverse scar tissue is characterised by fibroblast orientation across the wound and the presence of pseudolamellae - that is, bundles of collagen fibres (arrows) that connect with isodirected fibres of lamellae at both of the wound edges (WE). In the sagittal scar tissue, both fibroblasts and collagen fibres are oriented parallel to the wound (bar $=5 \mu \mathrm{m})$.
Regression analysis revealed a decrease in transverse fibroblast orientation in unsutured wound region (IV and) V over time $(\mathrm{p}<0.05)$ (Table 1). In contrast, sutured wounds showed an increase in transverse fibroblast orientation in regions I to III (and IV) over time $(p<0.05)$ (Table 2).

\section{Discussion}

In corneal transplant wounds (sutured), it has been documented that initial fibroblast orientation parallel to the wound eventually results in transverse - that is, pseudolamellar scar tissue, organisation..$^{1-3}$ In keratotomy wounds (unsutured), fibroblast orientation (and collagen fibre deposition) parallel to the epithelial plug was found to be associated with an ineffective scar tissue organisation parallel to the wound. ${ }^{1-1214}$ Further analysis of unsutured wounds in humans and monkeys, revealed a regional variation in healing over wound depth; anterior regions showed recovery of pseudolamellar continuity across the wound, whereas the mid posterior regions were found to be disorganised. ${ }^{12}$ Because unsutured incisions have epithelial plug remnants, a relatively low tensile strength, and a nontransparent slit-lamp appearance, keratotomy wound healing has clinically been interpreted as 'delayed'. ${ }^{2}$

In the current study, unsutured and sutured corneal wounds in monkeys were analysed by light and transmission electron microscopy, to study early phases of healing, and to explain the establishment of regional variation in healing over keratotomy wound depth. In early phases of healing in unsutured wounds, complete elimination of the epithelial plug appeared to be associated with transverse fibroblast orientation over the entire wound depth. In contrast, early sutured wounds showed a lack of scar tissue organisation with fibroblast orientation sagittal to the wound (Figs 2A and 2D). Since orientation of fibroblasts generally reflected orientation of collagen fibre deposition, ${ }^{12} 14$ cell orientation reflected the direction of repair and the potential recovery of corneal integrity. ${ }^{17}$ Our findings therefore indicate that unsutured wounds regain a more advanced healing morphology than sutured wounds at early postoperative time intervals (Tables 1 and 2).

In subsequent phases of healing, the approximation towards lamellar restoration in the unsutured wounds appeared to deteriorate. ${ }^{14}$ Fibroblasts that had a transverse orientation, showed progressive realignment sagittal to the wound, from the posterior toward the anterior scar (Figs 2A-C). Cell reorientation appeared concomitant with a breakdown of newly deposited pseudolamellae across the unsutured wound (Fig 3). During the same period, initially disorganised sutured wounds obtained a recovery of lamellar continuity across the wound, progressing from the anterior to posterior scar (Figs 2D-F). These changes indicate that in unsutured and sutured corneal wounds in monkeys, an early wound remodelling is 
established in opposite directions (Tables 1 and 2).

Better wound restoration of unsutured wounds in the early postoperative periods may have resulted from the presence of unsutured and sutured wounds within the same cornea, or from intrinsic corneal wound healing characteristics that are not related to our model. Unsutured wounds generally show delayed healing when compared with sutured wounds. ${ }^{13}$ Gaping may interfere with unsutured wound repair by subjecting the anterior wound to variations in intraocular pressure, eyelid movement, and/or tissue contraction at the wound edges. Although unsutured wounds may have gaped even more owing to tissue compression in adjacent sutured wounds, it is unclear how this would contribute to better wound restoration early in the postoperative period. The inflammatory reaction may have had an effect on both types of wounds within the same cornea. ${ }^{2}{ }^{18}$ In recent studies ${ }^{314}$ unsutured wounds appeared to heal faster in corneas containing adjacent sutured wounds. In those studies, the unsutured wounds, 2.5 months after surgery, showed a sagittal scar tissue organisation similar to control wounds in corneas without sutures at longer postoperative time intervals. The similarity in the morphology of late unsutured wounds in our previous and the present study, may indicate that the healing process of unsutured wounds in our model was not significantly altered by the adjacent sutured wounds.

In both types of wounds, the healing process was characterised by a biphasic fibroblast reaction - that is, cell orientation changed from one direction to another. Several factors have been documented to potentially regulate fibroblast orientation, such as chemotaxis (alignment over a chemical gradient), contact guidance (alignment along tissue structures), and stress distribution within the tissue (alignment to predominant stress forces). ${ }^{19}$ The changes in fibroblast orientation therefore suggest that at least two different cell directive mechanisms affect cell orientation during the healing of corneal wounds. In early phases, fibroblasts appeared to align to the wound edges (sagittal) in sutured wounds, and to the inferior border of the epithelial plug (transverse) in unsutured wounds. ${ }^{12}$ Contact guidance may therefore be an important cell directive factor in the early phases of healing in both types of wounds. ${ }^{8121920}$

But what factor(s) initiated cell reorientation over a $90^{\circ}$ angle in subsequent phases of healing, which resulted in a transverse cell orientation across sutured wounds, ${ }^{221}$ and a sagittal cell orientation in (mid posterior) unsutured wounds? Apparently, the new cell directive factor overruled the initial factor. In rabbit and cat models, reorientation of fibroblasts has been documented 41516 in non-perforating and perforating unsutured wounds. It was hypothesised that stress fibre orientation (and associated fibroblast orientation) may change from a transverse into a longitudinal orientation to the wound, because the stress induced by the intraocular pressure may be redistributed along the wound edges after wound contraction. ${ }^{16}$ However, this theory may not explain cell reorientation in sutured wounds. If the sutures eliminate the tangential forces across the (radial) wound, the eventual transverse scar tissue organisation can not be induced by stress forces across the wound. Furthermore, stress fibre bundles that characterise myofibroblasts, were not seen in unsutured or sutured wounds at any of the postoperative time intervals. Therefore, it is unclear what factors are responsible for cell reorientation during corneal wound healing. Early epithelial ingrowth seemed to reverse the biphasic fibroblast reaction. However, cell reorientation in both types of wounds may have resulted from different mechanisms.

Our study suggests that the initial approximation toward pseudolamellar wound repair and subsequent scar disorganisation represent normal healing phases or characteristics of unsutured wounds. ${ }^{14-16}$ Scar tissue organisation sagittal to the (mid posterior) wound, may then represent a final healing phase of unsutured wounds, and not an intermediate phase in an ongoing process toward recovery of lamellar continuity as seen in sutured wounds. In contrast with near anatomical repair of long term unsutured wounds in rabbits, ${ }^{9}$ the ineffective, long term unsutured wound healing morphology in monkeys resembles that in humans. ${ }^{12}$ If healing in monkeys is representative of that in humans, abnormal keratotomy wound healing morphology may not be 'delayed', as it is interpreted clinically. Instead, a different type of healing or tissue regeneration may develop, possibly induced by the initial presence of epithelium in unsutured wounds. This may explain the presence of regional variation in healing of unsutured corneal wounds. ${ }^{12}$ To our knowledge, regional variation in healing over the depth of sutured wounds has not been previously described.

In contrast with humans, the epithelial plug is expelled rapidly from the unsutured wound in monkeys, especially when sutures are present in adjacent wounds. ${ }^{14}$ Faster stromal wound closure may be due to a species difference, an age difference, or a lack of steroid therapy. However, underneath persistent superficial epithelial plugs in human radial keratotomy wounds, an asymmetry of the stromal scar architecture was found, similar to that of unsutured wounds in monkeys. ${ }^{12}$ At the inferior border of the plug, pseudolamellar repair was seen between the wound edges, whereas collagen deposition in deeper scar regions was disorganised (unpublished data). Since the initial pseudolamellar repair may result in recovery of tensile strength across the wound, ${ }^{17}$ subsequent ineffective remodelling may be expected to cause a progressive weakening of the wound, ${ }^{22}$ and more corneal flattening. Because wound healing varies among incisions within the same cornea and among individuals, ${ }^{3} 12$ variable degrees of weakening of the wounds may partially explain unpredictability of refractive outcome and/or progression in effect after radial keratotomy surgery. 
Supported by grants from the Department of Ophthalmology, University of Nijmegen, the Netherlands; the Flieringa Foundation and the Store Foundation, Rotterdam, the Netherlands; and the National Vision Research Institute; San Diego, USA.

We gratefully thank HD Wiersema; P M C A van Eerd, DVM; W M Klapwijk (TNO Primate Center, Delft, the Netherlands); F J R Rietveld (Department of Pathology, University of Nijmegen, the Netherlands); and J Hermans, PhD (Department of Medical Statistics, University of Leiden, the Netherlands) for their valuable advice and cooperation.

1 Binder PS. What we have learned about corneal wound healing from refractive surgery. Refract Corneal Surg 1989; 5: $98-120$.

2 Binder PS, Wickham MG, Zavala EY, Akers PH. Corneal anatomy and wound healing. In: Trans New Orleans Acad Ophthalmol St Louis: Mosby, 1980: 1-35.

3 Melles GRJ, Binder PS. A comparison of wound healing in sutured and unsutured corneal wounds. Arch Ophthalmol 1990; 108: 1460-9.

4 Jester JV, Petroll WM, Feng W, Essepian J, Cavanagh HD Radial keratotomy. I. The wound healing process and measurement of incisional gape in two animal models measurement of incisional gape in two animal models
using in vivo confocal microscopy. Invest Ophthalmol Vis using in vivo confocal mic
Sci 1992; 33: 3255-70.

5 Goodman WM, SundarRaj N, Garone M, Arffa RC, Thoft RA. Unique parameters in the healing of linear partial thickness penetrating corneal incisions in rabbit: immunohistochemical evaluation. Curr Eye Res 1989; 8: 305-16. 6 Jester JV, Steel D, Salz J, Miyashiro J, Rife L, Schanzlin DJ, Am $\mathcal{F}$ Ophthalmol 1981; 92: 153-71.

7 Lee RE, Davison PF, Cintron C. The healing of linear nonperforating wounds in rabbit corneas of different ages. perforating wounds in rabbit corneas of
Invest Ophthalmol Vis Sci 1982; 23: 660-5.

8 Cintron C, Szamier RB, Hassinger LC, Kublin CL. Scanning electron microscopy of rabbit corneal scars. Invest Ophthalmol Vis Sci 1982; 23: 50-63.

9 Cintron C, Hassinger LC, Kublin CL, Cannon DJ. Biochemical and ultrastructural changes in collagen during corneal wound healing. $\mathcal{F}$ Ultrastruct Res 1978; 65: 13-22.
10 Davison PF, Galbavy EJ. Connective tissue remodeling in corneal and scleral wounds. Invest Ophthalmol Vis Sci corneal and sclera

11 Jester JV, Villaseñor RA, Schanzlin DJ, Cavanagh HD. Variations in corneal wound healing after radial keratotomy: possible insights into mechanisms of clinical complications and refractive effects. Cornea 1992; 11: 191-9.

12 Melles GRJ, Binder PS, Anderson JA. Variation in healing throughout the depth of long-term, unsutured, corneal wounds in human autopsy specimens and monkeys. Arch Ophthalmol 1994; 112: 100-9.

13 Rock ME, Anderson JA, Binder PS. A modified Trichrome stain for light microscopic examination of plastic embedstain for light microscopic examination of plast

14 Melles GRJ, Binder PS. Effect of wound location, orientation, direction and postoperative time on unsutured corneal wound healing morphology in monkeys. Refract Corneal Surg 1992; 8: 427-38.

15 Garana RMR, Petroll WM, Chen WT, Herman IM, Barry P, Andrews P, et al. Radial keratotomy. II. Role of the myofibroblast in corneal wound contraction. Invest Ophthalmol Vis Sci 1992; 33: 3271-82.

16 Petroll WM, Cavanagh HD, Barry P, Andrews P, Jester JV. Quantitative analysis of stress fiber orientation during Quantitative analysis of stress fiber orientation during

17 Viola RS, Kempski MH, Nakada S, del Cerro M, Aquavella JV. A new model for evaluating corneal wound strength in JV. A new model for evaluating corneal wound strength in

18 Anderson JA, Murphy JA, Gaster RN. Inflammatory cel responses to radial keratotomy. Refract Corneal Surg 1989; 5: $21-6$.

19 Oster GF, Murray JD, Harris AK. Mechanical aspects of mesenchymal morphogenesis. F Embryol Exp Morph 1983; 78: 83-125.

20 Clark P, Connolly P, Curtis ASG, Dow JAT, Wilkinson CDW. Cell guidance by ultrafine topography in vitro. f Cell Sci 1991; 99: 73-7.

21 McGaw WT, Ten Cate AR. A role for collagen phagocytosis by fibroblasts in scar remodeling: an ultrastructural cytosis by fibroblasts in scar remodeling: an ultrastruct

$22 \mathrm{Hjortdal}$ JO. Influence of radial keratotomy on the regional mechanical performance of the human cornea. Invest Ophthalmol Vis Sci 1994; 35: 1790. 